\title{
Populasi
}

\section{Comparison of Child Health between Sandwich Generation and Non-Sandwich Generation}

\author{
Sri Yuliana \\ Faculty of Economics and Business, Universitas Indonesia, Depok \\ Corresponding Author: Sri Yuliana (email: yuliana.muhalimah@gmail.com)
}

\begin{abstract}
Sandwich Generation must treat two generations simultaneously and undoubtedly, having an impact on health in the sandwich generation, the previous generation, and the following generations. This study used IFLS data in 2007 and 2014 because IFLS provides longitudinal data that can see the relationship between sandwich generation households and children's health status with the Multinomial Logistics Regression method. The results showed that the $\mathrm{BMI}$ of non-sandwich generation children was higher than the group of sandwich generation children and was statistically significant, so it was concluded that there were differences in the average BMI between groups of sandwich generation children and non-sandwich generation children. BMR of sandwich generation children is lower than the group of not sandwich generation children and statistically significant, so with these results, it can be concluded that there is a difference in the average BMR between groups of sandwich generation children and non-sandwich generation children. The status of sandwich generation where relative to non-sandwich generation is only significant if the child is obese. Meanwhile, the status of the sandwich generation, which is relative to non-sandwich generation, significantly affects BMR for children in both the below-average BMR category and above-average BMR category for the overall sample.
\end{abstract}

Keywords: sandwich generation; child health; the Indonesian Family Life Survey (IFLS); Body Mass Index (BMI); Basal Metabolism Rate (BMR)

\section{Introduction}

The Indonesian government has also launched it through the Nawa Cita program, which is contained in the fifth program, i.e., improving the quality of life of Indonesian people. It also means improving child health status and in line with the formulation of the United Nations Development Program (UNDP) in the third objective of Sustainable Development Goals (SDGs), i.e., promoting healthy living and supporting welfare for all ages. One component of the human capital stock is child health (Becker, 1994; Bloom \& Canning, 2003; Bleakley, 2010). Childhood is an important period for development and well-being (Dowell \& Turner, 2014). The condition of children who are not getting enough nutrition (malnutrition) can hamper their ability as adults. If there is no balance of weight and height from the beginning, it will then affect the formation of the brain.

According to the Basic Health Research (2018) on nutritional, status of thin, very thin, 
and fat in toddlers has decreased. Nutritional status of very thin and thin was found in 2013 to 2018 , decreasing from 12.1 percent to 10.2 percent. Obesity status also declined from 11.8 percent to 8 percent. The decrease in obesity happened due to a decrease in stunting, as the development of toddlers' body lengthens. This is consistent with studies stating that stunted children have a BMI with fat or obese category (Savanur \& Ghugre, 2016).

Attention to demographic trends has been increasing in recent years, such as increasing life expectancy and decreasing fertility of the Indonesian population. Life expectancy in Indonesia is almost ten years longer to 73.0 years in 2018 compared to 1990 , which is 63.3 years, so with this life expectancy, more and more residents have parents who are still living above 65 years (BPS - Statistics Indonesia, 2018). Also, based on data from BPS - Statistics Indonesia (2019) the decline in fertility to 2.13 in 2018 compared to 1990 amounted to 3.33 married couples today tend to have fewer children and prefer to improve the quality of children rather than having to increase the number of children. The existence of these two demographic trends causes the dependency ratio in Indonesia will continue to rise from 2025 to 2045 to 53.35 , which means that in the future from 100 working-age population (15 to 64 years) will bear 53 young people (the next generation) and old age population (previous generation).

This phenomenon of the condition of a family that must care for the previous generation and care for the next generation is called "The Sandwich Generation" (Brody, 1981; Miller, 1981; Dautzenberg et al., 1998; Agree et al., 2003; Grundy \& Henretta, 2006). Increasing the number of household members that must be borne, can result in the increasingly confined circumstances of a person and / or a couple from the sandwich generation both financially and physically and mentally. Some researchers describe the sandwich generation as middle-aged adults aged 50-54 years who care for young people younger than 18 years and elderly parents simultaneously (Agree et al., 2003). While other studies illustrate that the sandwich generation consists of middle-aged parents who care for elderly parents and still help their children whose age is more than 18 years financially (Grundy \& Henretta, 2006).

The sandwich generation that must treat two generations simultaneously has an impact on the health of both the crushed generation and the generation before and after generations, especially for those who are workers. The focus to be examined in this study is the impact on child health because a healthy child is an investment in the future not only for parents, but also for the nation and country.

Based on the study conducted by $\mathrm{Li}$ et al., (2010); Watanabe et al., (2011) and Chambers et al., (2017), parents who have health problems tend to affect the health of their children as well, so policies related to parental health need to be improved to protect the health of children. Nutrition problems can occur in all age groups, both parents and children. Even nutritional problems in a certain age group will affect the nutritional status in the next life cycle period, meaning that if children experience nutritional problems since childhood will affect when they are adults (intergenerational impact). This study also uses the results of a study from Desai (1992) to know the relationship between child health and sandwich generation is associated with the concept of caregiving (family-size).

Therefore, this study attempted to see differences in literature by making observations in Indonesia using panel data. The use of longitudinal data helps in further analyzing how changes in health are caused if there is a change in family composition. Having a BMI of various categories must be balanced with physical activity that is appropriate for body weight and BMR, so that Chronic Energy Deficiency (CED) deficiency can be avoided (Shetty et al., 1992). 


\section{Comparison of Child Health between Sandwich Generation and Non-Sandwich Generation}

\section{Literature Review}

\section{Sandwich Generation}

A sandwich generation is a person who has the dual responsibility of caring for children and elderly parents simultaneously (Brody, 1981; Agree et al., 2003; Grundy \& Henretta, 2006; Derigne \& Ferrante, 2012). The care provided by the sandwich generation for their parents includes care in the home (e.g., homework, cooking), care outside the home (e.g., gardening, maintenance outside the home), transportation (e.g., shuttle, shopping) and personal care (e.g., bathing dress). According to Williams (2004), the time management of sandwich generation is done by reducing working hours and changing the schedule. As a result, their income can be reduced due to these matters. On the other hand, the sandwich generation that is classified as workers can also feel the burden in terms of health and social life.

The dual role the sandwich generations have can lead to poor health-increased stress and an inability to find balance in life (Marks, 1998), especially those who are classified as workers compared to people who only care for children or only parents who are more likely to experience health complaints. However, from the positive side, those who help the sandwich generation feel satisfied since they can give care for children and their parents. According to Marks (1998), sixty percent of the sandwich generation who worked at the same time caring for elderly parents and still caring for children at home felt that caring for parents was giving back what they had received, and seventy percent stated that their relationship with parents became stronger.

\section{Child Health in Sandwich Generation}

Health behaviours and health outcomes can be maintained even in the face of demanding tasks such as care for generations. Chassin et al. (2010) show the interaction between sandwich generation and health behaviour, i.e., 1) In terms of sandwich generation, people who feel themselves healthy will most likely take a dual role in caring; 2) people who take a dual role in care can receive several benefits from their responsibilities such as leading to better health behaviours; and 3) those who provide care may be specifically motivated to take care of their own health because others depend on them for care or because they observe a decrease in the health of others.

In the end, people who are in the sandwich generation have indirectly developed skills to handle task demands better than those who are not sandwich generation, so they can offset the negative effects of being in the sandwich generation. When sandwich generation is faced with multiple roles, there will be an effect on reducing time on the wrong priority of household matters, which is protecting the health of children (Gans \& Lowenstein, 2008).

\section{Body Mass Index (BMI)}

Body Mass Index (BMI) is an indicator of health that is adjusted to the size of weight and height. BMI is calculated as weight in kilograms divided by height squared in meters ( $\mathrm{kg} / \mathrm{m} 2$ ) (Centers For Disease Control and Prevention, 2011). Although BMI can be used as an indicator of obesity or obesity, BMI is more useful for measuring overweight compared to measuring excess fat in the body. Factors, such as gender, age, muscle mass, and ethnicity, can influence the relationship between BMI and body fat. However, BMI does not distinguish between excess fat, muscle or bone mass and cannot provide an indication of the distribution of fat in each individual's body. Another advantage of BMI can be used as an indicator of nutritional status that illustrates the state of past and present nutritional status by age (BMI / A). 
The most frequently measured measurements are Z-scores or percentiles (World Health Organization, 2006a). BMI is determined by measurements of weight and height, with the following formula:

$$
B M I=\frac{\text { weight }(\mathrm{kg})}{(\text { height })^{2}(\mathrm{~m})}
$$

\section{Basal Metabolic Rate (BMR)}

In addition to BMI, the child health indicator used in this study is the Basal Metabolic Rate (BMR). BMR is a minimum energy requirement needed by the body to carry out vital bodily processes which include the amount of energy needed for breathing, maintaining muscle mass, circulatory system, kidney work, pancreas, metabolic processes in cells, and maintaining body temperature. Approximately two-thirds of the energy released by a person a day is used for the needs of the body's metabolic activity. BMR is expressed in kilocalories per kilogram of body weight per hour. This number varies between people and maybe the same person if there is a change in physical and environmental conditions. There are several factors that influence BMR, including gender, age, body weight, body composition/body surface area, number of hours of sleep, health level, ambient temperature, body temperature, activity, hormone secretion, nutritional status, smoking habits, fever, hungry, pregnant and breastfeeding. Although BMI and BMR are calculated by paying attention to body weight, age and sex, the BMR is concerned with muscle mass factors. Therefore, in addition to paying attention to children's BMI factors, this study also attempted to compare the BMR of children aged 0-18 years.

According to World Health Organization (2006b), BMR values can be obtained by noting age, sex, and body weight which can be explained in the following.

\section{Table 1. Calculation of Basal Metabolism Rate (BMR) based on Age, Gender, and Weight}

\begin{tabular}{ccc}
\hline Age Group & $\begin{array}{c}\text { BMR (kcal/day) } \\
\text { for Men }\end{array}$ & $\begin{array}{c}\text { BMR (kcal/day) } \\
\text { for Women }\end{array}$ \\
\hline$<3$ & 59.512 weight $\mathrm{kg}-30.4$ & 58.317 weight $\mathrm{kg}-31.1$ \\
$3-10$ & 22.706 weight $\mathrm{kg}+504.3$ & 20.315 weight $\mathrm{kg}+485.9$ \\
$10-18$ & 17.686 weight $\mathrm{kg}+658.2$ & 13.384 weight $\mathrm{kg}+692.6$ \\
$18-30$ & 15.057 weight $\mathrm{kg}+692.2$ & 14.818 weight $\mathrm{kg}+486.6$ \\
$30-60$ & 11.472 weight $\mathrm{kg}+873.1$ & 8.126 weight $\mathrm{kg}+845.6$ \\
$\geq 60$ & 11.711 weight $\mathrm{kg}+587.7$ & 9.082 weight $\mathrm{kg}+658.5$ \\
\hline
\end{tabular}

Source: World Health Organization, 2006a

Relationship between Body Mass Index (BMI) and Basal Metabolism Rate (BMR)

Based on studies conducted by Shetty et al. (1992), when BMR was plotted against weight or height, there was a strong linear relationship in regression analysis. A sizable database analysis of BMR is measured prospectively that height and BMI contribute roughly in the same measure to variations in BMR. The addition of other variables hardly makes a difference in the strong correlations of weight and BMR. Comparison of correlation coefficients obtained in this study shows that BMR has a stronger correlation with body weight compared to other nutritional indices used as independent variables. The analysis shows weight accounts for 64 percent of the 


\section{Comparison of Child Health between Sandwich Generation and Non-Sandwich Generation}

variance, while BMI is 41 percent and height is 33 percent of the variance respectively.

The relationship between BMI and BMR is seen in people who are well-nourished and people with low BMI in developing countries and those who have increased degrees of obesity in western countries. BMI has approximately the same value for individuals; thus BMI can be a useful addition in achieving the desired level of energy needs of individuals or populations because BMR can be predicted from the optimal body weight obtained. Changes in body weight related to height, for example, weight loss or overweight, can affect the estimation of energy expenditure and energy requirements, because BMR is either predicted or measured, related to body weight. In this situation, the actual weight deviation from what is appropriate or desirable for the height will affect the estimated energy requirements, although defining the ideal terms for weight and height is not easy.

Chronic Energy Deficiency (CED) subjects (with BMI <18.5 but from lower socio-economic strata) have a relationship to weight and BMI with different BMR and separate from higher socio-economic strata. Because the relationship of body weight with BMR will be different in these groups, BMR is predicted to be different as well, and thus estimates of energy requirements will also vary significantly even though two individuals may have the same BMI even though they do not have the same bodyweight. Energy requirements of $50 \mathrm{~kg}$ active males with undernourished males (BMI <18.5) will be the same as predicted by the equations obtained from data on well-nourished adults (BMI> 18.5) if men come from social strata upper economy, but in men of the same weight from the lower socioeconomic group it will be $-12 \%$ lower. This observation also reinforces the statement that all individuals with a BMI $<18.5$ do not need CED based on a simple operational classification. Estimates of male energy requirements that are quite active are calculated using the factorial method of (a) the predicted BMR or (b) the measured BMR shows that these requirements can also be significantly lower if the individual is CED and from lower socioeconomic strata compared to underweight from high socioeconomic strata, even though both have identical BMI. For example, the energy needs of a fairly active adult male aged 18-29 years would be 10.5 MJ / day for people who are well-nourished, but only 9.0 MJ / day if the individual is CED, even though both have the same BMI. It is clear that CED individuals who also have shorter bodies, perhaps as a result of poor food intake since childhood, will have lower body weight for the same BMI value. The estimated energy requirements will thus not only be affected by an individual's BMI, but also an individual with a low BMI from a bad environment, shorter stature, metabolically different, or has a different body composition.

\section{The Presence of Children in the Household}

Generally, studies of the relationship of children's health and family size are discussed in the medical literature, which is more specific about health outcomes, such as diseases and diagnosis results that have been analyzed. Whereas in the economic and medical literature, the evidence showing the relationship between family size and health outcomes is largely quantitative. The difference between the medical literature and the economic literature can be seen clearly in the economic literature linking family size and children's health in terms of height, where family size, especially those with siblings, greatly influences children's height (Glick et al., 2007; Lawson \& Mace, 2008; Rosenzweig \& Zhang, 2009; Hatton \& Martin, 2010). Meanwhile, studies that refer to medical literature focus on more specific health outcomes, such as certain types of diseases such as fever, asthma, and allergies (Wickens et al., 1999; Karmaus \& Botezan, 2002) and not general health outcomes 
such as many studies of economic literature correlate with family size such as the number of siblings.

According to Bronte-Tinkewa \& Dejong (2004) and Palmer (2005), family level affects physical health status, such as stunting for children and mental health status that are mostly seen in people who get married without children living in the household, the group compared to groups of married people who live with children, and with groups of people who live without a partner who lives with children. The larger family size has an impact on children who are born and it can subsequently be seen from the low immunization and the level of consultation to health services, possibly reflecting the resource constraints of parents who find it difficult to find time to care for their children's health (Cameron et al., 2007; Lawson \& Mace, 2008). In line with Palmer (2005) study, a study conducted by Larson et al. (2008) revealed that households with a single parent affect children's health. In relation to the number of siblings, an only child has better health and nutrition compared to a child who has many siblings (Karmaus \& Botezan, 2002; Hesketh et al., 2003).

\section{Research Methods}

This study used panel data on the Indonesian Family Life Survey (IFLS) in 2007 (IFLS-4) and 2014 (IFLS-5). The reason in choosing IFLS data in this study is that because IFLS data provides longitudinal data that can see the relationship between sandwich generation households and children's health status (Strauss et al., 2016). The unit of analysis used in this study was children aged 0-18 years at IFLS-4 (20072008) and observed its progress until IFLS-5 (2014-2015).

The dependent variable in this study is the health of children aged 0-18 years which is seen from two indicators, i.e., Body Mass Index (BMI) and Basal Metabolic Rate (BMR). The main independent variable of this study is the status of the sandwich generation. What was included in the sandwich generation in this study is when a child lives at least with one parent and at least with one grandfather or grandmother. Meanwhile the control variables used in this study were age (child, head of household, mother), gender (child, head of household), length of school (children, head of household, mother), marital status of head of household, expenditure per capita, expenditure of members household, drinking water source, sanitation, and residential area (Wisana \& Samudra, 2017; Rizkiani, 2018).

Meanwhile, based on other study conducted by Rizkiani (2018) that used the influence of the mother's length of the school on children's nutrition, this study also linked to both the length of the school affected the child's BMI and BMR.

The analysis method used in this study is descriptive analysis and inferential analysis. This study used panel data and Multinomial Logistic Regression with marginal effect as the analysis model. Multinomial logistic regression with panel models is presented as follows:

$$
\operatorname{Pr}\left(y_{i t}=o_{j} \mid \alpha_{i}, \beta, x_{i t}\right)=\left\{\begin{array}{l}
\frac{\exp \left(\alpha_{i j}+x_{i t} \beta_{j}\right)}{1+\sum_{k \neq B} \exp \left(\alpha_{i k}+x_{i t} \beta_{k}\right)} j \neq B \\
\frac{1}{1+\sum_{k \neq B} \exp \left(\alpha_{i k}+x_{i t} \beta_{k}\right)} j=B
\end{array}\right.
$$




\section{Results and Analysis}

The status of the natural sandwich generation in this study was that children lived at least with one parent and also at least lived with grandparents in one household. Figure 1 shows the transition to changes in sandwich generation status in the two survey periods.

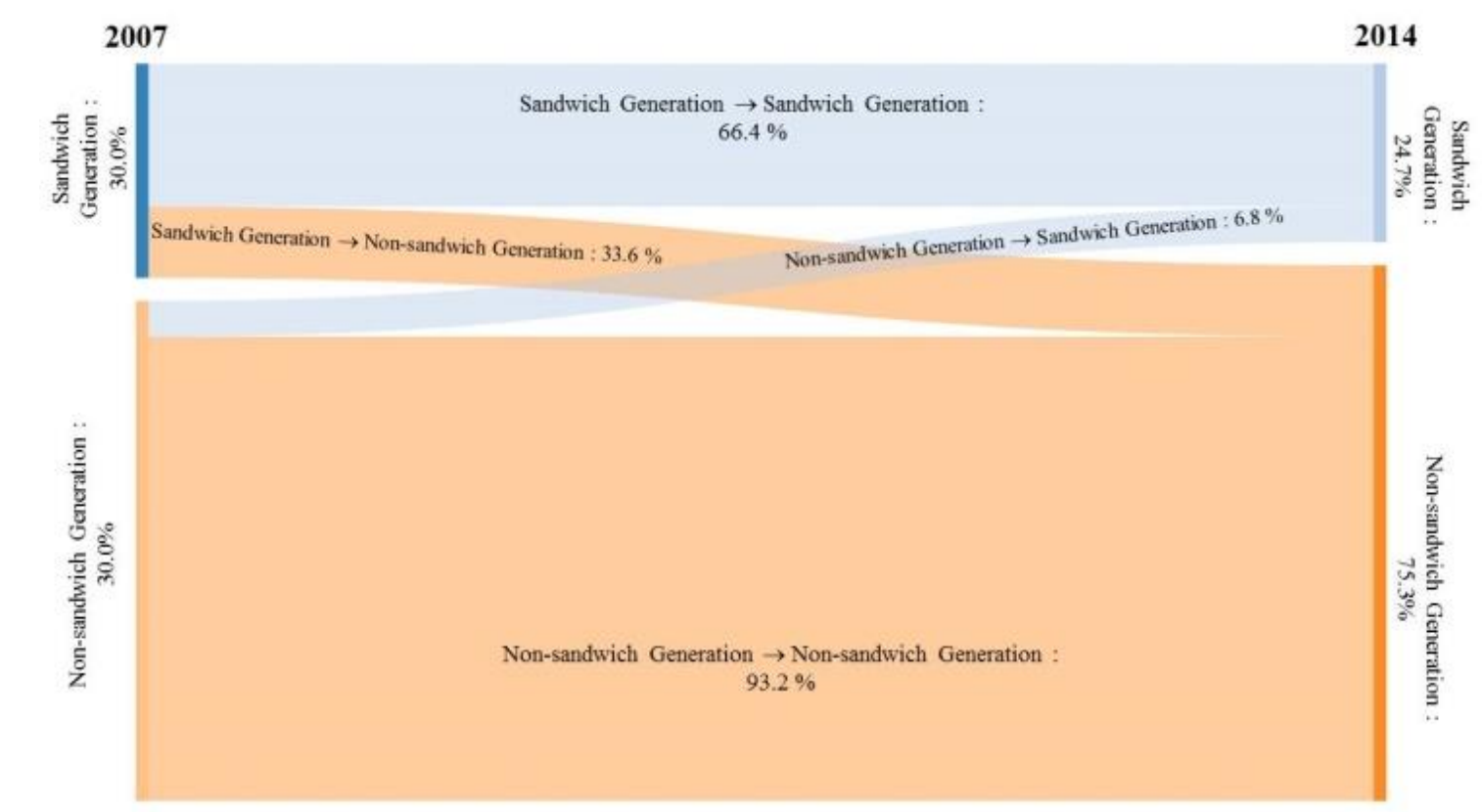

Source: IFLS-4 and IFLS-5, reprocessed data

Figure 1. Sandwich Generation Status Transition, 2007 and 2014

There was a decrease in families belonging to the sandwich generation from 2007 by 30.0 percent to 24.7 percent in 2014. This can be seen from the more family transition of 33.6 percent, which was previously the sandwich generation in 2007 , to non-sandwich generation in 2014. This is likely due to elderly parents who have died, or the sandwich family has separated from their parents to live separately and independently with their children. Meanwhile, only 6.8 percent of families who were not previously the sandwich generation in 2007 were included in the sandwich generation family group in 2014. This might happen due to a marriage, where young married couples have not been able to live financially independently, or they have not been allowed to live apart from parents.
Figure 2 shows the transition of changes in Body Mass Index (BMI) or Body Mass Index (BMI) in the two survey periods. 77.9 percent of children were classified as having a normal BMI, while 8.7 percent were classified as thin, 7.4 percent were classified as fat, and 6.0 percent were obese in the 2007 survey period. Children classified as thin experienced a decrease of 7.2 percent in 2014; in contrast, fat and obese children increased by 10.3 percent and 6.5 percent respectively in 2014, this is in line with the results of the Basic Health Research, (2018). An increase in the fat and obesity categories is likely due to a changing diet. The increase was seen in the transition from a previously normal change in children to obese by 9.0 percent and 4 percent in the change to obesity. These figures indicate that Indonesia 
is still experiencing nutritional problems of obese children because the country is said to no longer have nutritional problems if the indicator of overweight children is under 5 (World Health Organization, 2010). The increasing number of overweight and obesity in children is likely due to children tend to like unhealthy foods such as fast food/ junk food, rarely eat fruit and vegetables, and parents less having healthy life to their children. The increasing number of middleclass tendencies to visit fast food places and department stores that serve nutrientdeficient foods is increasing as what has been supported by government policies that easily provide permits for the establishment of fast food franchises, department stores, and malls that also improve the consumptive lifestyle of the Indonesian population.

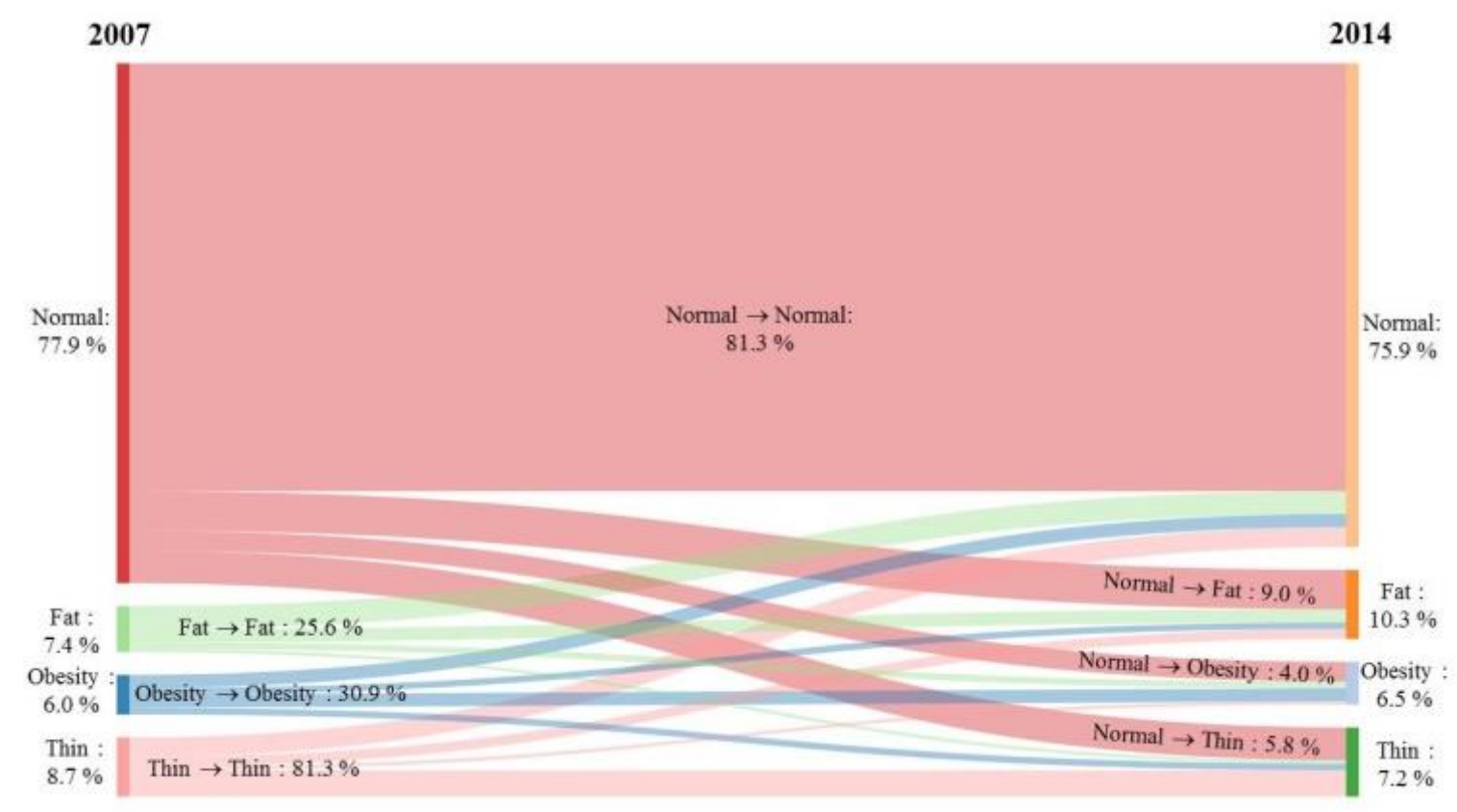

Source: IFLS-4 and IFLS-5, reprocessed data

Figure 2. Body Mass Index Transition (BMI), 2007 and 2014

A total of 6,008 children classified as nonsandwich generation, showed processing results with an average BMI of $18.52 \mathrm{~kg} / \mathrm{m}^{2}$, while 2,196 children who are in the sandwich generation have an average BMl of $17.90 \mathrm{~kg} /$ $\mathrm{m}^{2}$.

If the status of the sandwich generation was compared to each BMI category shown in Figure 3 the children with lean BMl from sandwich generation would fell by almost about 2 percent over the two survey periods. The most significant increase was seen in children with obese BMI, both from the sandwich generation and non-sandwich generation experiencing an increase of 10.86 percent and 10.20 percent, respectively, when they were older. This is triggered by an unhealthy lifestyle and lack of sports activities to burn bad fats that can cause obesity and obesity.

Figure 3 shows the transition to changes in Basal Metabolic Rate (BMR) in the two survey periods. Since there is no classification from WHO, this study used a benchmark of average values. 54.4 percents of the children had the BMR on average, while 23.7 percent of them had BMR below the average, and 22.0 percent of them were still classified 


\section{Comparison of Child Health between Sandwich Generation and Non-Sandwich Generation}

as having a BMR above the average in the 2007 survey period. The increase occurred in children with a BMR above the average in 2014 by 28.5 percent. This is in line with the increase in BMl due to weight gain in children who are not adjusted to sports and other activities. Whereas a decrease of 53.5 percent and 18.1 percent in 2014 occurred in children with an average BMR and children with a BMR below the average. Only 3.0 percent of children had changed the condition from BMR above the average to BMR below the average, while 2.5 percent of them happened conversely, i.e., children who changed their condition from BMR below the average to BMR above the average.

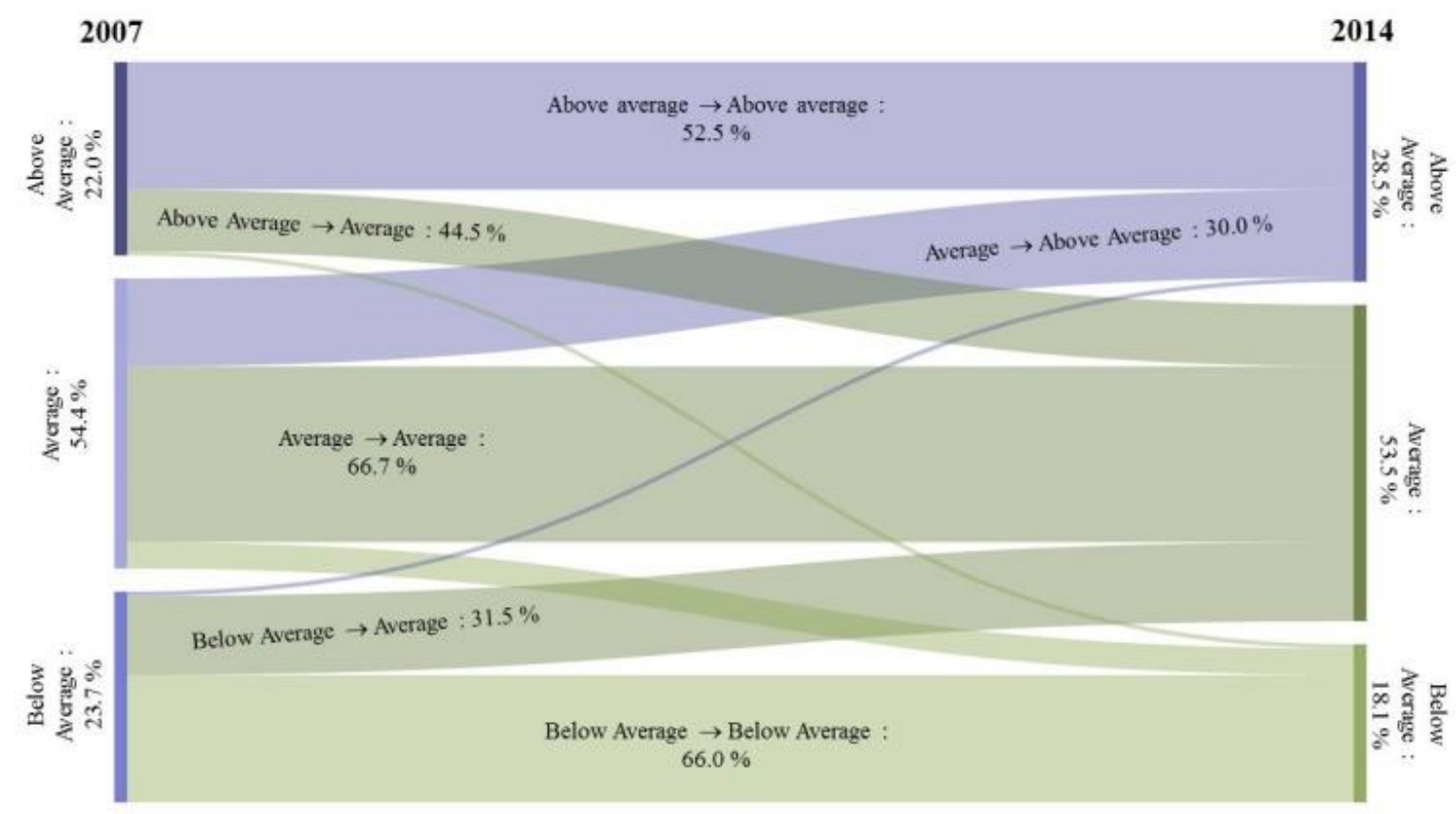

Source: IFLS-4 and IFLS-5, reprocessed data

Figure 3. Basal Metabolic Rate (BMR) Transition, 2007 and 2014

The panel data processing results in Appendix 1 show that sandwich generation, relative to non-sandwich generation, is only significant if the child is obese, meaning that children who are in the sandwich generation have a higher chance of being obese. For household characteristic variables, only the sanitation variable is not significant to children's health, and this has also been shown in the average difference test in the previous descriptive analysis. The variable number of household members has significant effects when a child is classified as thin and obese when the number of household members increases the chances of a child having a lean BMI and obesity are lower. Household expenditure has the same significant influence as the number of household members per capita, but the chances of a child experiencing obesity BMI will be higher as per capita household expenditure increases. Housing and drinking water sources have significant effects when a child is classified as overweight and obese while living in urban areas and having a decent source of drinking water that will increase opportunities to become fat and obese.

The ages of both parents have significant effects when their children have a chance to experience obesity but has the opposite effect. Increasing the age of the mother will 
reduce the chances of the child for being fat, but when the mother enters a certain age, it will increase the chances of the child to be overweight. Increasing the age of the head of the household will increase the chances of the child for being fat. By sex, girls have a lower chance of being obese than boys. The length of school period has a different effect among the head of the household, mother, and child. The length of school period of the household head has significantly effects when the child is obese. The opportunity for children to be obese will be even greater when the length of the school head of the household increases. However, mother's school period significantly affects when the child is overweight, i.e., the chance of the child for being obese increases when the length of her mother's school period increases in one year. Conversely, increasing the length of child's school period has an impact on the decrease in child's chance for being thinner.

The regression results in Appendix 2 show that most of the independent variables significantly affect the Basal Metabolism Rate (BMR). Sandwich generation status, which is relative to non-sandwich generation, has a very significant influence on children's BMR both in the below-average category and above the average BMR in the whole sample but has the opposite effect. This means that children who are in the sandwich generation have a higher chance of having a below-average BMR. Conversely, children who are in the sandwich generation have a lower chance of having an above-average BMR. In general, if you pay attention to the chances of each variable to be the opposite or reverse between BMR below the average and BMR above the average. This can certainly be ascertained because if the child has a lower chance in the BMR category below the average, it will create a higher chance in the BMR category above the average, and vice versa. However, different things happen to the age of the mother, both in the category of below average and above average, the age of the mother causes a higher chance of a child experiencing BMR in both categories. The age of the head of the household and the age of the child also significantly influence BMR. In contrast to the influence of the mother's age, the age of the head of the household and the age of the child if they are one year old will reduce the chances of the child having a below-average BMR.

The sex of the child only significantly influences the BMR above the average, where girls relative to boys have a lower chance. In line with to BMI, sanitation variables and marital status of head of household did not significantly affect BMR of children aged 0-18 in various categories. Conversely, increasing maternal age still increases the chances of children having BMR below the average or above average.

Increasing household expenditure per capita will also increase the chances of children having a BMR below the average and BMR above the average, while an adequate source of drinking water relative to an inadequate source of drinking water will reduce the chances of children having a BMR below the average compared to having an average BMR.

The average difference test using an independent $t$-test was used to determine differences in children's health and other characteristics between the two groups, i.e., the group of children from the sandwich generation and the group of children from non-sandwich generation, both on IFLS-4 and IFLS-5. The results of the independent $t$-test are presented in Appendix 1.

Based on the results of processing shows that the BMI of non-sandwich children generation is higher than the group of children of sandwich generation with an average difference of $0.62 \mathrm{~kg} / \mathrm{m}^{2}$, with a $p$-value $<0.05$ or statistically significant. It can be concluded that there are differences in the average BMI between sandwich-generation children and non-sandwich-generation children. The BMR 


\section{Comparison of Child Health between Sandwich Generation}

and Non-Sandwich Generation

in sandwich generation group was lower than the non-sandwich generation group with an average difference of $43.77 \mathrm{kcal} /$ day with $p$-value $<0.05$ or statistically significant, so there were differences in the average BMR between the children of sandwich generation and the children of non-sandwich generation.

The age of both the head of households, mothers, and children are statistically significant where $p$-value $<0.05$, meaning that there are differences in the average age between the sandwich generation and the non-sandwich generation, where parents of sandwich generation have an average older age but has an average age of younger children with a different value of 1.567 years for children, $-4,966$ years for mothers, and -7,561 years for heads of households. This indicates that although the age of the heads of the households and the mothers of the sandwich generation families is older, they have young children compared to the non-sandwich families. There was no difference in average and was not statistically significant, but it showed differences by sex of household heads between sandwich generation and non-sandwich generation, as well as statistically significant differences.

Based on the length of school period, both children and parents between the sandwich generation and the non-sandwich generation had average statistically significant differences of $p$-value $<0.05$. The length of school period of parents in the sandwich generation was lower than that of parents who were in non-sandwich generation, with an average ratio of 1.05 for household heads and 0.77 for differences in mother school duration, respectively. Likewise, the same thing happened to the average length of school period of children, where the sandwich generation was lower than the non-sandwich generation. The marital status of the heads of the households also had an average difference between the sandwich generation and the non-sandwich generation and was statistically significant.
Of the five household characteristics used in this study, only sanitation that was statistically insignificant and had no average difference that is too far between the sandwich generation and the non-sandwich generation. This may happen because most households in Indonesia already have adequate and adequate defecation facilities. The non-sandwich generation has a greater average in terms of per capita household expenditure categories, residential areas, and drinking water sources compared to the sandwich generation. In contrast, the sandwich generation has a larger average in terms of the number of household members compared to the non-sandwich generation. This could clearly answer since the sandwich generation also lived with the older generation, i.e., grandparents.

The author also tried to use the variable number of children as a comparison of differences affecting the variable number of household members. Since the unit of analysis is children and the objective of this study is to find out the differences in the health of children of sandwich generation and the non-sandwich generation, the assumption of the use of the variable number of children owned by each household has more impact in answering the objective. However, based on the different test, the average was not statistically significant with $p$-value $>0.05$, where the sandwich generation had an average number of children of 2.42 people with a standard deviation of 1.29. Meanwhile, the non-sandwich generation had an average number of 2.40 children with a standard deviation of 1.49 , so this study preferred using the variable number of household members to the variable number of children in inferential analysis.

\section{Discussion}

The panel data processing results showed that the children of sandwich generation had a higher chance of being 
obese. These results are in line with a study conducted by Li et al., (2010); Watanabe et al., (2011) and Chambers et al., (2017) who stated that children of sandwich generation who live with and are raised by their grand parents have worse health than those who do not live with and are raised by their grandparents, where the child is more at risk of obesity.

When the number of household members increases the chances of a child having a thin BMI and obesity are lower. This can be attributed to a study conducted by Desai (1992) showing that the effect of family size on well-being depends on the extent to which parents bear the costs of raising their children. As governments privatize and reduce their role in providing food, health care, and education, parents will be increasingly responsible for the well-being of children.

Chances of children experiencing BMIbased obesity will be higher when household expenditure increases. More specifically, a study conducted by Sari et al. (2017) indicated that only the expenditure of food sources of animal protein was significant with a reduction in the incidence of stunting.

Housing and drinking water sources having significant effects on children who are classified as overweight and obese, were living in urban areas and having a decent source of drinking water that will then increase the chance to become fat and obese. Indonesian children who live in cities are very likely to experience obesity or obesity due to a lifestyle that prefers fast food that is not good for health. This is in contrast to a study conducted by Amaral et al. (2017) in Uganda, which stated that children who live in rural areas are more likely to experience stunting. That is because most children aged 12 months or less have not consumed good food for their growth and development period.

Increasing maternal age will reduce the chance of a child for being obese, and this is in line with the study conducted by Myrskylä \& Fenelon (2012) who found that children who were born from mothers aged under 25 years or over 35 years have worse health outcomes compared to those who were born from mothers aged 25-34 years due to height and obesity. Conversely, increasing the age of the household head will increase the chance of the child for being fat. This is supported by the results of the study conducted by Robertson (2018) which showed that the age of fathers also has an impact on the risk of infant congenital diseases, where babies are more susceptible to disease if they come from fathers aged over 45 years.

Girls have a lower chance for being obese than boys. The Jawaregowda \& Angadi (2015) also shows differences in nutritional status between boys and girls. The existence of gender bias in the way parents take care of children, such as differences in feeding and breastfeeding is one of the causes of differences in nutritional achievement between boys and girls.

The results of BMR processing show that the age of children who if they are one year old will reduce the chances of children having BMR below the average. This can be explained through research conducted by Lazzer et al. (2010) which states that the decrease in BMR related to age is caused by a decrease in Fat-Free Mass (FFM). FFM is also known as lean body mass, referring to all body components except fat. This includes the content of water, bones, organs, and muscles of the body. However, when associated with body weight and body composition, FFM mainly refers to muscle mass. It is assumed that as children get older, the physical activity of children increases so that the chances of children having BMR below the lower average. As people age, they can reduce the metabolic rate of specific organ tissues. The underlying mechanism for explaining the effects of FFM and age may require measurement of cellular levels in the estimation of BMR (Sabounchi et al., 2013).

Conversely, the sex of child only significantly affects the BMR above the 
average, where girls relative to boys have a lower chance. This is because, in children and adolescents, a higher BMR occurs in men where their FFM is higher than that of women (Lazzer et al., 2010).

\section{Conclusion}

The results confirmed that 77.9 percent of children were still classified as having a normal BMI, while 8.7 percent of them were classified as thin, 7.4 percent were classified as obese, and 6.0 percent were obese in the 2007 survey period. Around 7.2 percent in 2014, the obese children experienced an increase of 10.3 percent and 6.5 percent in 2014 respectively. This is in line with the results of the Basic Health Research (2018). The BMR distribution pattern of children based on the status of the family sandwich generation in 2007 and 2014 showed a different pattern. Children from the sandwich family had a smaller distribution in 2007 or at a younger age. Conversely, when the age of children is older in 2014, the distribution of BMR sandwich generation children is greater. BMR is related to body weight; if weight is reduced, the BMR will then automatically be reduced as well. The higher the body weight, the more body cells/body mass must be supported or need energy. Meanwhile, if one loses his weight, then the cells that must be supported are also reduced.

The BMI of non-sandwich generation children was higher than the sandwich generation children and is statistically significant, so it is concluded there is an average difference in BMI between sandwich generation children and non-sandwich children. The BMR of sandwich generation was lower than that of the non-sandwich generation and statistically significant, so there were differences in the average BMR between the sandwich generation and the non-sandwich children.

The sandwich generation, which is relative to non-sandwich generation, is only significant if the child is obese, meaning that the sandwich generation children have a higher chance of being obese. Meanwhile, the status of sandwich generation, which is relative to non-sandwich generation, is very significantly affecting the BMR of children both in the BMR category below the average and the BMR above the overall average of the sample, meaning that the chances of the sandwich generation children are higher to have a below-average BMR. Conversely, the chances of sandwich generation children are lower for having an above-average BMR.

Therefore, based on the results of the study, the sandwich generation children tend to have a BMI that is inversely proportional to BMR, especially if they are likely to be obese. This may occur due to poor food intake since they were child so they have a high BMI but a below-average BMR (Motulsky \& Chairman, 1989). The estimation of energy requirements will thus not only be affected by individual BMI but also whether individuals with low or high BMI are actually from a bad environment, are shorter in stature, are metabolically different and have different body compositions (Shetty et al., 1992). Basically, when the increase in BMI must be followed by the increase in BMR, changes in body weight associated with height, example e.g., being underweight or overweight, can affect the estimation of energy expenditure and energy requirements, because BMR is either predicted or measured, related to body weight.

The limitation of this study is that the variables related to the elderly could not be used if a comparison was made between the sandwich generation and the non-sandwich generation since the sample of the nonsandwich generation was not present, so the effect of the presence of the elderly could only be observed in the sandwich generation family. In addition, the Basal Metabolic Rate (BMR) used to date still does not have a uniform standard regarding the cut off standards of the FAO / WHO / UNU. The 
absence of a standard cut off is expected that FAO / WHO / UNU can provide an ideal classification of BMR or not the same as the classification for BMI (FAO et al., 2001).

Meanwhile, suggestions for further study are to specifically analyze the health of children in sandwich generation, so the characteristics of the grandparents can be included in the study and compared for the health of three generations (children's health, sandwich generation's health, and elderly health) between sandwich generation families and non-sandwich generation.

\section{References}

Agree, E., Bissett, B., \& Rendall, S. M. 2003. Simultaneous care for parents and care for children among mid-life British women and men. Population Trends, (112), 29-35.

Amaral, M. M., Herrin, W. E., \& Gulere, G. B. 2017. Using the Uganda National Panel Survey to analyze the effect of staple food consumption on undernourishment in Ugandan children. BMC Public Health, 18(32). https://doi.org/10.1186/s12889017-4576-1.

Badan Pusat Statistik. 2018. Angka Harapan Hidup. Retrieved from https://www.bps. go.id/site/pilihdata.html.

Badan Pusat Statistik. 2019. Fertilitas. Retrieved from https://www.bps.go.id/ site/pilihdata.html.

Becker, G. S. 1994. Human Capital: A Theoretical and Empirical Analysis with Special Reference to Education (3rd Edition). In G. S. Becker (Ed.) (3rd Editio, pp. 15-28). The University of Chicago Press.

Bleakley, H. 2010. Health, Human Capital, and Development. Annu Rev Econom, 2, 283-310. https://doi.org/10.1146/ annurev.economics.102308.124436. Health.

Bloom, D., \& Canning, D. 2003. Health as Human Capital and its Impact on
Economic Performance. The Geneva Papers on Risk and Insurance, 28(2), 304-315.

Brody, E. M. 1981. "Women in the Middle" and Family Help to Older People. The Gerontologist, 21(5), 471-480. Retrieved from https://doi.org/10.1093/ geront/21.5.471.

Bronte-Tinkewa, J., \& Dejong, G. F. 2004. Children's nutrition in Jamaica: do household structure and household economic resources matter? Social Science \& Medicine, 58(3), 499-514. Retrieved from https://doi.org/10.1016/j. socscimed.2003.09.017.

Cameron, M., Lim, S., \& Lim, S. 2007. Household resources, household composition, and child nutritional outcomes Paper presented at the Australian Agricultural and Resource Economics Society conference , Queenstown , 13-16 February 2007 Household resources , household composition, and child nutritional outcomes, (February), 13-16.

Centers For Disease Control and Prevention (CDC). 2011. Body Mass Index : Considerations for Practitioners.

Chambers, S. A., Rowa-dewar, N., Radley, A., \& Dobbie, F. 2017. A systematic review of grandparents' influence on grandchildren's cancer risk factors. Plos One, 12(11), 1-28. Retrieved from https:// doi.org/10.1371/journal.pone.0185420

Chassin, L., Macy, J. T., Seo, D.-C., Presson, C. C., \& Sherman, S. J. 2010. The association between membership in the sandwich generation and health behaviors: A longitudinal study. Journal of Applied Developmental Psychology, 31(1), 38-46. Retrieved from https://doi. org/10.1016/j.appdev.2009.06.001.

Dautzenberg, M. G. H. ., Diederiks, J. P. M. ., Philipsen, H., \& Stevens, F. C. J. 1998. Women of a Middle Generation and Parent Care. The International Journal of Aging \& Human Development, 47(4), 
241-262. Retrieved from https://doi. org/10.2190/6WPY-8020-R57X-H31K.

Derigne, L., \& Ferrante, S. 2012. The Sandwich Generation: A Review of the Literature, 95-104.

Desai, S. 1992. The impact of family size on children's nutritional status: insights from a comparative perspective. Retrieved from https://www.popline.org/ node/325649

Dowell, A., \& Turner, N. 2014. Child health indicators: from theoretical frameworks to practical reality? British Journal of General Practice, (December), 608-609. https://doi.org/10.3399/bjgp14X682585.

FAO, WHO, \& UNU. 2001. Human energy requirements.

Gans, D., \& Lowenstein, A. 2008. A Cross National Comparison of Simultaneous Multigenerational Support: The "Sandwich Generation" Revisited. The Oasis Journal.

Glick, P. J., Marini, A., \& Sahn, E. 2007. Estimating the Consequences of Unintended Fertility for Child Health and Education in Romania: An Analysis using Twins Data. Oxford Bulletin of Economics and Statistics, 69(5), 667691.

Grundy, E., \& Henretta, J. C. 2006. Between elderly parents and adult children: a new look at the intergenerational care provided by the 'sandwich generation.' Ageing \& Society, 26(5), 707-722. https:// doi.org/10.1017/S0144686X06004934.

Hatton, T., \& Martin, R. M. 2010. The effects on stature of poverty, family size, and birth order: British children in the 1930s. Oxford Economic Papers, 62(1), 157184.

Hesketh, T., Qu, J. D., \& Tomkins, A. 2003. Health effects of family size: cross sectional survey in Chinese adolescents. Arch Dis Child, 88, 467-471.

Jawaregowda, S. K., \& Angadi, M. M. 2015. Gender differences in nutritional status among under five children in rural areas of Bijapur district, Karnataka, India. International Journal of Community Medicine and Public Health, 2(4), 506-509. Karmaus, W., \& Botezan, C. 2002. Does a higher number of siblings protect against the development of allergy and asthma? A review. J Epidemiol Community Health, 56, 209-217.

Kementerian Kesehatan Republik Indonesia. 2018. HASIL UTAMA RISKESDAS 2018.

Larson, K., Russ, S. A., Crall, J. J., \& Halfon, N. 2008. Influence of Multiple Social Risks on Children 's Health. Pediatrics, 121(2). https://doi.org/10.1542/peds.2007-0447.

Lawson, D. W., \& Mace, R. 2008. Sibling configuration and childhood growth in contemporary British families. International Journal of Epidemiology, 37, 1408-1421. https://doi.org/10.1093/ ije/dyn116.

Lazzer, S., Bedogni, G., Lafortuna, C. L., Marazzi, N., Busti, C., Galli, R., ... Sartorio, A. 2010. Relationship Between Basal Metabolic Rate, Gender, Age , and Body Composition in 8,780 White Obese Subjects. Obesity, 18(1), 71-78. https://doi.org/10.1038/oby.2009.162.

Li, L., Abbas, J., \& Law, C. 2010. Is childcare associated with the risk of overweight and obesity in the early years ? Findings from the UK Millennium Cohort Study. International Journal of Obesity, 34(7), 1160-1168. https://doi.org/10.1038/ ijo.2010.15.

Marks, N. F. 1998. Does It Hurt to Care? Caregiving, Work-Family Conflict, and Midlife Well-Being. Journal of Marriage and Family, 60(4), 951-966.

Miller, D. A. 1981. The "Sandwich" Generation: Adult Children of the Aging. Social Work, 26, 419. Retrieved from https://eric. ed.gov/?id=EJ250894

Motulsky, A. G., \& Chairman. 1989. Diet and Health: Implications for Reducing Chronic Disease Risk.

Myrskylä, M., \& Fenelon, A. 2012. Maternal Age and Offspring Adult Health: Evidence 
From the Health and Retirement Study. Demography, 49(4). https://doi. org/10.1007/s13524-012-0132-x.

Palmer, R. 2005. The Family Contribution to Health Status: A PopulationLevel Estimate. ANNALS OF FAMILY MEDICINE, 102-108. https://doi. org/10.1370/afm.266.INTRODUCTION

Rizkiani, D. 2018. Pengaruh pola konsumsi individu dan rumah tangga terhadap status nutrisi anak tesis.

Robertson, S. 2018. Association of paternal age with perinatal outcomes between 2007 and 2016 in the United States: population based cohort study. BMJ.

Rosenzweig, M., \& Zhang, J. 2009. Do Population Control Policies Induce More Human Capital Investment? Twins, Birth Weight and China's "One-Child" Policy. Review of Economic Studies, 76(3), 1149-1174.

Sabounchi, N. S., Rahmandad, H., \& Ammerman, A. 2013. Best Fitting Prediction Equations for Basal Metabolic Rate: Informing Obesity Interventions in Diverse Populations. International Journal of Obesity (London), 37(10), 1364-1370. https://doi.org/10.1038/ ijo.2012.218.

Sari, M., Bloem, M. W., Pee, S. de, \& Sun, K. 2017. Higher Household Expenditure on Animal-Source and Nongrain Foods Lowers the Risk of Stunting among Children 0-59 Months Old in Indonesia : Implications of Rising Food Prices Higher Household Expenditure on Animal-Source and Nongrain Foods Lowers the Risk. Journal of Nutrition, (November 2009). https://doi. org/10.3945/jn.109.110858.

Savanur, M., \& Ghugre, P. 2016. BMI, body fat and waist-to-height ratio of stunted v. non-stunted Indian children: a case-control study. Public Health Nutrition, 19(8), 1389-1396. https://doi. org/10.1017/S1368980016000215
Shetty, P. S., Soares, M. J., \& James, W. P. T. 1992. Body mass index: its relationship to basal metabolic rates and energy requirements. Retrieved from http:// www.nzdl.org/gsdlmod? $e=d-00000$ 00---off-0fnl2.2--00-0----0-10-0---0--0direct-10---4-------0-1|--11-en-50--20-about---00-0-1-00-0--4----0-0-1110-0utfZz-8-00\&a $=d \& c=f n \mid 2.2 \& \mathrm{cl}=\mathrm{CL}$ 2.8\&d=HASH0158494c16dde1e28989 $7 d 62.5 .5$

Strauss, J., Witoelar, F., \& Sikoki, B. 2016. The Fifth Wave of the Indonesia Family Life Survey : Overview and Field Report (Vol. 1).

Watanabe, E., Lee, J. S., \& Kawakubo, K. 2011. Associations of maternal employment and three-generation families with pre-school children's overweight and obesity in Japan. International Journal of Obesity, 35(7), 945-952. https://doi. org/10.1038/ijo.2011.82.

Wickens, K., Crane, J., Pearce, N., \& Beasley, R. 1999. The magnitude of the effect of smaller family sizes on the increase in the prevalence of asthma and hay fever in the United Kingdom and New Zealand. Journal of Allergy and Clinical Immunology, 104(3), 554-558.

Williams, C. 2004. The sandwich generation. Statistics Canada, (75), 5-12.

Wisana, I. D. G. K., \& Samudra, R. R. 2017. Female Labor Force Participation of Sandwich Generation in Indonesia. Research Gate, (March).

World Health Organization (WHO). (2006a). Child Growth Standards.

World Health Organization (WHO). (2006b). Length/height-for-age, weight-for-age, weight-for-length, weight-for-height and body mass index-for-age : Methods and development.

World Health Organization (WHO). (2010). Nutrition Landscape Information System (NLIS) Country Profile Indicators. 


\section{Appendix 1. Multinomial Logistic Regression Results with Margins Effects on the Body Mass Index (BMI) Variable, 2007 and 2014}

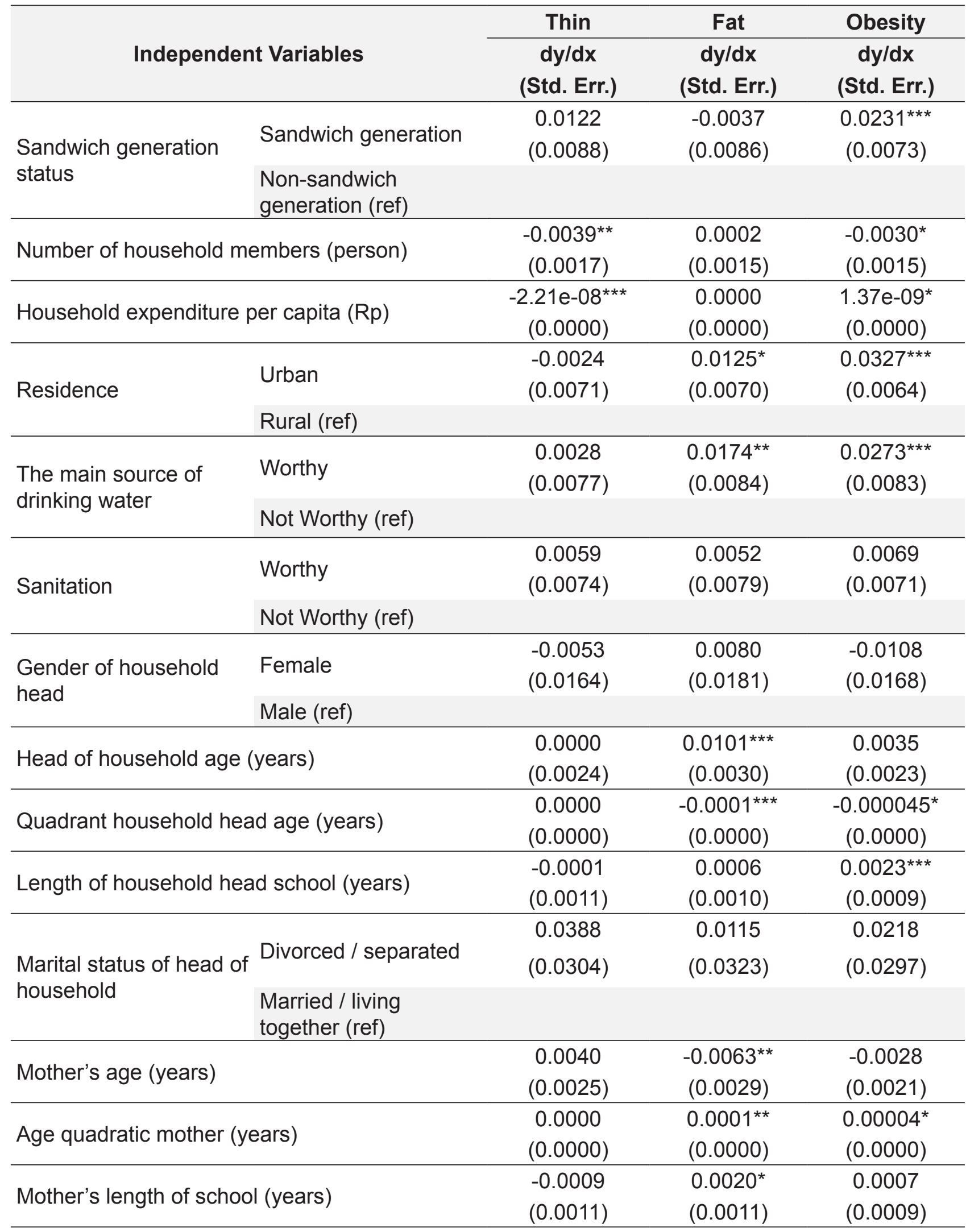




\begin{tabular}{lcccc}
\hline \multirow{2}{*}{$\begin{array}{l}\text { Child's gender } \\
\text { Female }\end{array}$} & -0.0053 & 0.0027 & $-0.0136^{* *}$ \\
& Male (ref) & $(0.0063)$ & $(0.0065)$ & $(0.0055)$ \\
\hline \multirow{2}{*}{ Age of child (years) } & & & \\
\hline \multirow{2}{*}{ Age of quadratic child (years) } & 0.0009 & 0.0008 & -0.0011 \\
& $(0.0022)$ & $(0.0025)$ & $(0.0019)$ \\
\hline \multirow{2}{*}{ Years of school education (years) } & 0.0001 & 0.0000 & 0.0000 \\
& $(0.0001)$ & $(0.0001)$ & $(0.0001)$ \\
\hline
\end{tabular}

Note: * sig at $p<0.1 ;{ }^{* *}$ sig at $p<0.05 ;{ }^{* * *}$ sig at $p<0.01$

Source: IFLS-4 and IFLS-5, have been reprocessed

\section{Appendix 2. Multinomial Logistic Regression Results with Margins Effects on the Basal Metabolic Rate (BMR) Variable, 2007 and 2014}

\begin{tabular}{|c|c|c|c|c|}
\hline \multirow{2}{*}{ Independent Variables } & \multicolumn{2}{|c|}{ Below-average } & \multicolumn{2}{|c|}{ Above-average } \\
\hline & dy/dx & Std. Err. & dy/dx & Std. Err. \\
\hline \multicolumn{5}{|l|}{ Sandwich generation status } \\
\hline Sandwich generation & $0.1008^{* * *}$ & 0.0120 & $-0.0746^{* * *}$ & 0.0132 \\
\hline \multicolumn{5}{|l|}{ Non-sandwich generation (ref) } \\
\hline $\begin{array}{l}\text { Number of household members } \\
\text { (person) }\end{array}$ & $-0.0275^{* * *}$ & 0.0033 & $0.0138^{* * *}$ & 0.0022 \\
\hline $\begin{array}{l}\text { Household expenditure per capita } \\
\text { (Rp) }\end{array}$ & $-0.0000^{* * *}$ & 0.0000 & $0.0000^{* * *}$ & 0.0000 \\
\hline \multicolumn{5}{|l|}{ Residence } \\
\hline Urban & $-0.0266^{* * *}$ & 0.0090 & $0.0356^{* * *}$ & 0.0106 \\
\hline \multicolumn{5}{|l|}{ Rural (ref) } \\
\hline \multicolumn{5}{|l|}{$\begin{array}{l}\text { The main source of drinking } \\
\text { water }\end{array}$} \\
\hline Worthy & $-0.0304^{* * *}$ & 0.0097 & 0.0162 & 0.0121 \\
\hline \multicolumn{5}{|l|}{ Not Worthy (ref) } \\
\hline \multicolumn{5}{|l|}{ Sanitation } \\
\hline Worthy & 0.0041 & 0.0098 & 0.0029 & 0.0116 \\
\hline \multicolumn{5}{|l|}{ Not Worthy (ref) } \\
\hline \multicolumn{5}{|l|}{ Gender of household head } \\
\hline Female & $-0.0470^{* *}$ & 0.0233 & 0.0028 & 0.0262 \\
\hline \multicolumn{5}{|l|}{ Male (ref) } \\
\hline Head of household age (years) & $-0.0158^{* * *}$ & 0.0037 & $0.0314^{* * *}$ & 0.0049 \\
\hline $\begin{array}{l}\text { Quadrant household head age } \\
\text { (years) }\end{array}$ & $0.0001^{* * *}$ & 0.0000 & $-0.0003^{* * *}$ & 0.0000 \\
\hline $\begin{array}{l}\text { Length of household head school } \\
\text { (years) }\end{array}$ & 0.0008 & 0.0014 & -0.0001 & 0.0016 \\
\hline \multicolumn{5}{|l|}{$\begin{array}{l}\text { Marital status of head of } \\
\text { household }\end{array}$} \\
\hline Divorced / separated & 0.0448 & 0.0465 & 0.0421 & 0.0484 \\
\hline \multicolumn{5}{|l|}{ Married / living together (ref) } \\
\hline Mother's age (years) & $0.0093^{* * *}$ & 0.0033 & $0.0184^{* * *}$ & 0.0054 \\
\hline
\end{tabular}



and Non-Sandwich Generation

\begin{tabular}{lcccc} 
Age quadratic mother (years) & $-0.0001^{* * *}$ & 0.0000 & $-0.0002^{* * *}$ & 0.0001 \\
$\begin{array}{l}\text { Mother's length of school (years) } \\
\text { Child's gender }\end{array}$ & -0.0007 & 0.0014 & $0.0028^{*}$ & 0.0016 \\
$\begin{array}{l}\text { Female } \\
\text { Male (ref) }\end{array}$ & 0.0107 & 0.0080 & $-0.0691^{* * *}$ & 0.0095 \\
$\begin{array}{l}\text { Age of child (years) } \\
\text { Age of quadratic child (years) }\end{array}$ & $-0.0536^{* * *}$ & 0.0032 & $0.0153^{* * *}$ & 0.0035 \\
Years of school education (years) & $-0.0019^{* * *}$ & 0.0002 & $-0.0007^{* * *}$ & 0.0001 \\
\hline
\end{tabular}

Note: *sig at $p<0.1 ;{ }^{* *}$ sig at $p<0.05 ;{ }^{* * *}$ sig at $p<0.01$

Source: IFLS-4 and IFLS-5, have been reprocessed 